\title{
FINISHING OF BEEF AND LAMB
}

\author{
L . R . McMillan \\ Farmer, R.D., Ongarue
}

The FARM, situated $56 \mathbf{~ k m}$ south of Te Kuiti, is of 300 ha of which 285 ha are in grass. There are 33 paddocks mostly watered by natural streams. Good access to the farm is by a county road which runs $2.5 \mathrm{~km}$ through the centre of the property.

The contour is roughly a third steep hills, a third rolling, and a third flat. The steep country is mostly sandstone, with some greywacke and rhyolite. The easier country consists of Taupo ash to varying depths, to give a sandy, silty soil, and the flats are a water-sorted Taupo ash, which is just pumice.

Apart from the very steep areas, the soil is free draining and able to carry large numbers of cattle through the winter and an even higher population of grass grub all the year round.

The climate, particularly in summer, has been unpredictable since 1969. Summer growth used to be good, but since the drought of 1970 and the dry years since, King Country summers have become unreliable. The winters, however, are still true to form, lasting about four months and providing 50 to 80 frosts in that time, including frosts up to $11^{\circ} \mathrm{C}$. However, reasonably good spring growth can be expected from the end of August. Rainfall is normally $1500 \mathrm{~m}$ each year, but not as well spread as it used to be.

Since most of the soils are derived from Taupo ash, heavy applications of phosphate have been necessary. The farm is now at the potash-responsive stage and so this is applied as well. In August all but the silage and hay paddocks receive $375 \mathrm{~kg} / \mathrm{ha}$ of $15 \%$ potassic superphosphate.

The silage areas receive $375 \mathrm{~kg}$ superphosphate plus $60 \mathrm{~kg}$ urea/ha. No potash is sown at this time as I find the best silage is made with a grass-dominant sward. In early autumn, however, when these same areas are closed for cattle wintering, they receive $500 \mathrm{~kg} / \mathrm{ha}$ of $50 \%$ potassic superphosphate plus $60 \mathrm{~kg} / \mathrm{ha}$ urea. Areas to be cut for hay are closed in December and receive $375 \mathrm{~kg} / \mathrm{ha}$ of $30 \%$ potassic superphosphate.

Details of stock numbers over recent years now follow. As can be seen from Table 1, breeding ewe numbers have declined 
TABLE 1: STOCK NUMBERS AND LAMBING PERCENTAGES, 1966-73

\begin{tabular}{ccccc}
\hline & $\begin{array}{c}\text { Breeding } \\
\text { Ewes }\end{array}$ & $\begin{array}{c}\text { Total } \\
\text { Sheep }\end{array}$ & Lambing $\%$ & $\begin{array}{c}\text { Total } \\
\text { Cattle }\end{array}$ \\
\hline 1966 & 1950 & 2910 & 119 & 265 \\
1967 & 2050 & 3030 & 117 & 280 \\
1968 & 2100 & 3140 & 107 & 200. \\
1969 & 2200 & 3300 & 121 & 320 \\
1970 & 2200 & 3300 & 90 & 200 \\
1971 & 2200 & 2930 & 100 & 150 \\
1972 & 2000 & 2850 & 103 & 245 \\
1973 & 1850 & 2620 & & 305 \\
\hline
\end{tabular}

some 300 over the past few years. But of more importance is the drop in lambing percentage from the 1960s and I will comment more on this later. The number of cattle wintered has tended to fluctuate from year to year depending on conditions at the time.

Total stock units as at July 1 and stocking rate/ha are shown in Table 2. The main point again is the drop after the 1969-70 drought and the slow but gradual build-up since then.

TABLE 2: STOCK UNITS AND STOCKING RATES, 1966-73

\begin{tabular}{lcccc} 
& Sheep E.E. & Cattle E.E. & Total E.E. & $\begin{array}{c}\text { Total E.E. } \\
\text { Grassed ha }\end{array}$ \\
\hline 1966 & 2600 & 1145 & 3745 & 13.2 \\
1967 & 2710 & 1250 & 3960 & 13.9 \\
1968 & 2780 & 1000 & 3780 & 13.3 \\
1969 & 2925 & 1410 & $433 \mathrm{~s}$ & 15.2 \\
1970 & 2925 & 1000 & 392.5 & 13.8 \\
1971 & 2670 & 750 & 3420 & 12.0 \\
1972 & 2560 & 1070 & 3630 & 12.7 \\
1973 & 2360 & 1350 & 3710 & 13.0 \\
\hline
\end{tabular}

Because of the rather severe winter conditions, early lambing is difficult so the emphasis on my lamb finishing policy is to get weights of about $13 \mathrm{~kg}$ and to halve as many lambs as possible. So a high lambing percentage is my aim and I hope to get back to previous levels.

The ewes, most of them Romneys, are mainly mated to a Romney ram at the beginning of April. But each year about 300 Romney ewes are mated to Border Leicester rams in early March. This is to provide sufficient replacements to maintain a 
small flock of crossbreds which have more vigour, are easier lambing, and thrive better on the steeper hills. This crossbred flock is mated to Down rams in early March and the progeny fatten quickly.

Incidentally, the Border Leicester $\times$ Romney ewe hoggets do very well. Jn the autumn they averaged $32 \mathrm{~kg}$ and were mated at that time. For the past three seasons ram harnesses have been usd to help lifit lambing percentages. It enables me to cull dry and late-lambing ewes before the winter. Also, early lambing ewes are identified for better feeding.

Lambing dates are staggered to ease the burden on labour. From experience I know it is worth while to spend time with the ewes over lambing. Lambs' are drenched at least once while on the ewe and are normally weaned at the end of November. Any prime lambs are sold at this time, and those remaining are drenched, crutched and sprayed for fly strike before going into fresh paddocks. At all times the top wether lambs are grazed separately and 'another draft is taken out just before shearing. Similarly, the top ewe lambs, my future flock replacements, are grazed by themselves.

Shearing takes place about three weeks after weaning. At this stage the top wether lambs are grazed on the clover regrowth on silage paddocks. This strong clover growth enables me to draft an above-average number of lambs over the January to February period. Normally 60 to $70 \%$ of works lambs have gone by about the first week in February. Then, during autumn, lambs are spread out as thinly as possible to reduce the effects of pneumonia. This 'has become serious during the drier years, a problem I believe I share with most other King Country farmers. Lambs are drenched monthly, depending on the weather, and by the end of May all the works lambs have been drafted.

Only dry cattle are farmed, and, to take advantage of spring and summer growth, as many as possible are wintered. This is done by feeding a lot of silage and hay as well as nitrogenboosted, autumn-saved grass. Because so much of the winter ration is silage or hay, growth weight gains during this period are limited. It is for this reason that medium to top weaners are purchased to ensure that good slaughter weights are achieved by the following 'autumn. Eighteen-month-old cattle are also wintered and these are carried because of the flexibility they offer with respect to feeding and to sale. The actual ratio of weaner to 1\&month-old cattle this last winter was 50: 50 which is the proportion I now consider desirable to have. So apart from 
these general principles, the number and type of cattle wintered depend on .winter supplements available, how good or bad the autumn growth has been, and prices on the store market.

To summarize my cattle finishing policy, I like to buy 225 to ' $270 \mathrm{~kg}$ liveweight weaners, most of which are finished at carcass weights of $225 \mathrm{~kg}$ from January onwards. Some of the smaller yearlings would be retained for another winter. These, together with the bought-in 18-month-old cattle, are killed at carcass weights. of up to $300 \mathrm{~kg}$, depending on the season. These older cattle can go to the works at any time of the year.

I farm the traditional breeds, usually Angus, and do so be'cause they are readily available. Most of the cattle bought are steers, but I have fattened heifers and shall continue to do so. They can be cheaper to buy and are quicker to turn over, and for these reasons are financially very worth while.

I would like now to outline the feeding management for the different classes of cattle. Overall the 300 cattle would be wintered with 1500 bales of hay and 300 tonnes of silage available. This is 3300 bales of hay equivalent or 10 to 11 bales per head that could be fed. I plan to get through the winter with some hay heft over and normally this doles happen. Although I consider it inefficient to carry too much hay or silage forward from one year to the next, I like to have enough surplus for an emergency.

This last winter 130 of the better weaners were self-feeding a 200-tonnes stack of silage. I like silage because it is cheaper than hay to make and easier to harvest. The fact that it does not have to be fed out in the morning with a 12" frost is a relief also. This silage has been cut from 10 ha which give 20 tonnes of settled silage harvested/ha. Such a high yield cut normally in November is possible because of the use of nitrogen. The silage lasts for three months, from mid-June to mid-September, giving a daily feeding rate of $18 \mathrm{~kg} / \mathrm{head} / \mathrm{day}$. In addition, the weaners are break-fed using a front and a back fence on 10 ha of autumn-saved pasture. The rotation is continued on wintergrown grass, This gives a stocking rate of 13 weaners/ha over that critical winter period. Once the silage is finished, the system is kept going at the same stocking rate using hay for as long as is necessary. While the cattle are on silage, my aim is to maintain their weights, but winter growth weight gains of 0.15 $\mathrm{kg} / \mathrm{head} /$ day are normally achieved.

Once spring growth is under way, these weaners are sorted -out into two mobs. The best are the fattening mob and from 
spring onwards are grazed separately from sheep at all times till slaughter.

During spring and early summer, daily growth weight gains of between 1.2 and $1.4 \mathrm{~kg} / \mathrm{head} /$ day are realized. Over the late summer period, however, good liveweight gains are hard to get. This concerns me and is something I would appreciate more information on; I believe Ruakura has been looking into this problem.

The medium weaners are spread out as thinly as possible with sheep to keep pastures in order for ewes. and lambs. As the top cattle are finished these medium ones are progressively drafted into the fattening mob. During this period scales are used to determ\&e which cattle go where and this applies to any similar changes made with the other classes of cattle. A second, much smaller mob of lighter weaners is normally wintered on a crop. This cropping is done as a means of pasture improvement and is only about 2 ha each year. However, these areas are undersown in the spring with oats and yield a very valuable crop of 250 bales/ha of oat hay.

This winter, 30 lighter weaners were on 2 ha of very indifferent looking swedes plus two bales of hay/day, just to keep the battens on the fence. In the spring these cattle would join the medium weaners spread out with the sheep.

This brings me now to the grazing management of the older cattle. Again, these are wintered as several different mobs. There is one group of 35 to 40 forward 18-month-old steers of 340 to $385 \mathrm{~kg}$ liveweight. They are self-fed on silage and break-fed $\mathbf{c m}$ grass, similar to the weaner set-up. A 50 tonne stack of silage is made from 3.25 ha. At $23 \mathrm{~kg}$ silage/head/day, silage lasts for two months. During this time the stocking rate on the saved pasture is 10/ha and again the system is kept going with hay till the end of September. I have no weight gain records to confirm it, but I am sure these cattle continue to grow through this period.

Another mob of 25 to 30 fat 18-month-old cattle is wintered on autumn-saved grass with small 'amounts of hay. These are making growth weight gains and are sold to the local trade as prices rise.

For two years now I 'have undersown areas with Tama ryegrass for use as a specialized green-feed, fattening crop. This winter I had $301 \&$ month-old heifers break-grazing 5 ha, supplemented with three bales of hay. This gives a stocking rate of 6 heifers/ ha and daily growth weight gains in excess of $0.5 \mathrm{~kg} / \mathrm{head}$ are 
achieved. These would be sold to the local trade in the early spring when prices are high.

During spring and summer the top two-year-old cattle would be grazed separately from sheep. But the top yearlings get the best, and the two\&year-dds are utilizing feed not so suitable for the younger cattle. This, in fact, is one of the main reasons for having the two classes of "cattle.

So far I have accounted for 260 of the 300 on hand on July 1 . The balance would be made up of dairy-beef-type oattle wintered on the steep hill country where they survive on fern and fresh air. The other 20 cattle on hand on July 1 went to the works soon af terwards.

I have made some brief reference to the use of scales. Though not employed as often as they should be, they are used to sort out forward cattle to put into the finishing mob. Another use is to weigh cattle before they go to the works. Once the killing sheet is back, it is a little late to deoide then that the cattle should have been held for another month.

In conclusion, it can be seen that my basic policy with respect to lamb finishing would be similar to that of other King Country farmers who are fattening and rearing their own replacements. However, there are two aspects I would like to emphasize. I have mentioned the use of nitrogen on silage areas to give a grassdominant swat-d. The main reason for doing this, however, is because of the dominant clover regrowth that occurs, In fact it is as good as that achieved by chemical means.

In particular, 12 ha are shut up after harvesting and these are initially grazed with 50 top wether lambs/tha. There is no doubt that this system has enabled me to get many more lambs away in January and February than was possible before.

I also place a lot of emphasis on a high lambing percentage. The fact that I have still not got back to 115 to $120 \%$ concerns me. No doubt this is due to the carry-over effects of light weight two-tooth replacements entering rhe flock, particularly in the 1970 drought year, and in some of the other dry years since then. Perhaps we have tended to under-estimate the carry-over effects of a bad season on our more highly stocked sheep farms.

With respect to my cattle finishing policy, the main points are the emphasis on flexibility, feed budgeting and the use of nitrogen. This flexibility is achieved in several ways. By farming only dry stock, there are no basic breeding stock to be wintered. I buy just the number that can be wintered on the feed available, hence the importance of feed budgeting. But flexibility with 
feeding is also achieved by having both weaners and 18-monthold cattle. The young cattle can utilize with greatest efficiency the high; quality spring grass. Summer grass surpluses of lower food value can be used to \#advantage by older cattle that will still make good growth weight gains. Then I have flexibility at the selling end because at most times of the year I can have cattle sufficiently forward to sell well if feed gets short.

Over the past four years a major development has been the use of artificial nitrogen fertilizers. Each year up to 55 ha would receive nitrogen either in spring or autumn to provide extra feed for cattle. I consider that nitrogen fertilizer, together with break-feeding using a back fence, has been the key to improved wintesing on my farm.

Finally, I would like to say that the policies outlined have evolved over a period and are still developing. Any modification made would be beoause there is more profit in it. The farm is regarded as a business and success in this direction adds very much to the satisfaction of farming as a way of life. 